\title{
Nutritional Stress Induced by Tryptophan-Degrading Enzymes Results in ATF4- Dependent Reprogramming of the Amino Acid Transporter Profile in Tumor Cells
}

Timosenko, Elina; Ghadbane, Hemza; Silk, Jonathan D; Shepherd, Dawn; Gileadi, Uzi; Howson, Lauren J.; Laynes, Robert; Zhao, Qi; Strausberg, Robert L.; Olsen, Lars Rønn

Total number of authors:

14

Published in:

Cancer Research

Link to article, DOI:

10.1158/0008-5472.CAN-15-3502

Publication date:

2016

Document Version

Peer reviewed version

Link back to DTU Orbit

Citation $(A P A)$ :

Timosenko, E., Ghadbane, H., Silk, J. D., Shepherd, D., Gileadi, U., Howson, L. J., Laynes, R., Zhao, Q., Strausberg, R. L., Olsen, L. R., Taylor, S., Buffa, F. M., Boyd, R., \& Cerundolo, V. (2016). Nutritional Stress Induced by Tryptophan-Degrading Enzymes Results in ATF4-Dependent Reprogramming of the Amino Acid Transporter Profile in Tumor Cells. Cancer Research, 76(21), 6193-6204. https://doi.org/10.1158/00085472.CAN-15-3502

\section{General rights}

Copyright and moral rights for the publications made accessible in the public portal are retained by the authors and/or other copyright owners and it is a condition of accessing publications that users recognise and abide by the legal requirements associated with these rights.

- Users may download and print one copy of any publication from the public portal for the purpose of private study or research.

- You may not further distribute the material or use it for any profit-making activity or commercial gain

- You may freely distribute the URL identifying the publication in the public portal 


\section{Nutritional stress induced by tryptophan-degrading enzymes results in ATF4- dependent reprogramming of the amino acid transporter profile in tumor cells}

Elina Timosenko ${ }^{1}$, Hemza Ghadbane ${ }^{1, \dagger}$, Jonathan D. Silk ${ }^{1, \dagger}$, Dawn Shepherd ${ }^{1}$, Uzi Gileadi ${ }^{1}$, Lauren J. Howson ${ }^{1}$, Robert Laynes ${ }^{2}$, Qi Zhao ${ }^{3,}$, Robert L. Strausberg ${ }^{3}$, Lars R. Olsen ${ }^{4}$, Stephen Taylor ${ }^{5}$, Francesca M. Buffa ${ }^{6}$, Richard Boyd ${ }^{2}$, and Vincenzo Cerundolo ${ }^{1}$

${ }^{1}$ MRC Human Immunology Unit, Weatherall Institute of Molecular Medicine, University of Oxford, John Radcliffe Hospital, Oxford, OX3 9DS, UK

${ }^{2}$ Department of Physiology, Anatomy and Genetics, University of Oxford, Oxford, OX1 3QX, UK

${ }^{3}$ Ludwig Cancer Research, New York, NY 10017, USA

${ }^{4}$ Center for Biological Sequence Analysis, Department of Systems Biology, Technical University of Denmark, Lyngby, 2800, Denmark

${ }^{5}$ The Computational Biology Research Group (CBRG), Weatherall Institute of Molecular Medicine, University of Oxford, John Radcliffe Hospital, Oxford, OX3 9DS, UK

${ }^{6}$ Department of Oncology, Old Road Campus Research Building, University of Oxford, Oxford, OX3 7DQ, UK

${ }^{\dagger}$ Current address: Immunocore Ltd, 101 Park Drive, Milton Park, Abingdon, OX14 4RY, UK

${ }^{\dagger}$ Current address: Adaptimmune Ltd, 91 Park Drive, Milton Park, Abingdon, OX14 4RY, UK

${ }^{*}$ Current address: Regeneron Pharmaceuticals, Inc., 777 Old Saw Mill River Road, Tarrytown, NY 10591, USA

Corresponding Author: Vincenzo Cerundolo, MRC Human Immunology Unit, Weatherall Institute of Molecular Medicine, University of Oxford, Oxford, OX3 9DS, UK. Phone: +44(0)1865 222412; Fax: +44(0)1865 222502; E-mail: vincenzo.cerundolo@imm.ox.ac.uk 
Running title: Reprogramming of amino acid transporters in $\mathrm{IDO}^{+}$tumor cells

Keywords: Cancer immune escape; indoleamine 2,3-dioxygenase; amino acid transport;

SLC1A5; tumor microenvironment

This work was supported by Cancer Research UK (Programme Grant \#C399/A2291), the Ludwig Institute for Cancer Research, the Harry Mahon Cancer Research Trust, UK, and the Medical Research Council.

The authors disclose no potential conflicts of interest.

Word Count: 5,999

Total number of figures: 6 Research. 


\begin{abstract}
Tryptophan degradation is an immune escape strategy shared by many tumors. However, cancer cells' compensatory mechanisms remain unclear. We demonstrate here that a shortage of tryptophan caused by expression of indoleamine 2,3-dioxygenase (IDO) and tryptophan 2,3-dioxygenase (TDO) resulted in ATF4-dependent up-regulation of several amino acid transporters, including SLC1A5 and its truncated isoforms, which in turn enhanced tryptophan and glutamine uptake. Importantly, SLC1A5 failed to be up-regulated in resting human $\mathrm{T}$ cells kept under low tryptophan conditions, but was enhanced upon cognate antigen $\mathrm{T}$ cell receptor engagement. Our results highlight key differences in the ability of tumor and T cells to adapt to tryptophan starvation and provide important insights into the poor prognosis of tumors co-expressing IDO and SLC1A5.
\end{abstract}




\section{Introduction}

Indoleamine 2,3-dioxygenase (IDO) and tryptophan 2,3-dioxygenase (TDO) are ratelimiting enzymes of the kynurenine pathway, which converts the essential amino acid (EAA) tryptophan to kynurenine. IDO-mediated tryptophan degradation, long recognized as an antimicrobial resistance mechanism, has now been firmly established as a key metabolic regulator of the immune response in a number of settings, including maternal/fetal interface, autoimmunity and cancer. An increasing number of studies have demonstrated that tryptophan catabolism is an important mechanism of immune escape exploited by IDO- and TDO-expressing tumors. Many human cancers constitutively express IDO $(1,2)$ and TDO $(3,4)$, and acquisition of these tryptophan-degrading enzymes by immunogenic tumors prevents their rejection by tumor-specific $T$ cells $(1,3)$. Furthermore, high IDO expression correlates with poor clinical prognosis in several human cancers (5) and plays an immunosuppressive role in the context of immunotherapies (6).

Starvation of cells from tryptophan and other amino acids is sensed through the general control nonderepressible protein 2 (GCN2) kinase pathway, which is activated in response to accumulation of uncharged tRNA. Upon activation, GCN2 phosphorylates the translation initiation factor eIF2 $\alpha$, which promotes translation of the master regulator of the integrated stress response, activating transcription factor 4 (ATF4) (7). ATF4 regulates transcription of a spectrum of genes required for amino acid synthesis and import, redox balance and angiogenesis $(8,9)$.

While it is known that in T cells, IDO-mediated tryptophan depletion induces a GCN2dependent proliferative arrest (10), inhibiting the G1-to-S phase transition $(11,12)$, the molecular mechanisms by which IDO- and TDO-expressing cancer cells remain resistant to local tryptophan depletion remain largely unknown. To address this question, we performed whole transcriptome sequencing of HeLa cells expressing IDO, and compared this 
transcriptome profile to that of IDO- HeLa cells or of HeLa cells treated with gamma interferon (IFN $\gamma)$ - a known inducer of endogenous IDO expression $(11,12)$. These results have led to the demonstration that overexpression of tryptophan-degrading enzymes IDO and TDO in tumor cells results in the up-regulation of several amino acid transporters, and in particular of SLC1A5 - a sodium-dependent high-affinity glutamine transporter of the solute carrier family (SLC) $1(13,14)$, which is overexpressed in several human cancers.

In this study, we establish a causative relationship between IDO-mediated tryptophan degradation and SLC1A5 up-regulation, and characterize the dichotomy of this phenomenon in tumor cells and T lymphocytes. 


\section{Materials and Methods}

\section{Cell lines and culture media}

The HeLa, A431, DX3, HPAF and DU145 tumor cell lines were obtained from Cancer Research UK. Cell line characterizations were performed by the cell bank using Short Tandem Repeat (STR) profiling. Cell lines were kept frozen and were passaged in the user's laboratory for fewer than 6 months after resuscitation. HeLa cells were cultured in Minimum Essential Medium supplemented with 10\% fetal bovine serum (FBS). A431, DX3 and HPAF cells were maintained in Dulbecco's Modified Eagle Medium (DMEM) supplemented with 10\% FBS. DU145 cells were cultured in RPMI 1640 medium supplemented with 10\% FBS. Customized DMEM depleted of tryptophan, glutamine, arginine, leucine, isoleucine, glycine and serine (Life Technologies) was supplemented with 10\% dialysed FBS (Life Technologies) and the missing amino acids accordingly.

\section{Transcriptome sequencing (RNA-seq)}

RNA-seq was performed as described in the Supplementary Materials and Methods. The data has been deposited in the GEO database (GEO accession GSE75956).

\section{Measurement of ${ }^{3} \mathrm{H}$-labelled amino acid uptake}

Cells were washed twice in PBS, followed by a 20 min incubation at $37^{\circ} \mathrm{C}$. $\left[{ }^{3} \mathrm{H}\right] \mathrm{L}-$ tryptophan or $\left[{ }^{3} \mathrm{H}\right] \mathrm{L}$-glutamine (both from PerkinElmer) were added to the cells at $50 \mathrm{pmol} / \mathrm{ml}$ and $200 \mathrm{pmol} / \mathrm{ml}$, respectively, for a fixed time at $37^{\circ} \mathrm{C}$. Uptake was stopped by removing the solution and adding 20mM L-lysine in ice-cold PBS. The cells were lysed with $1 \% \mathrm{NaOH}, 0.1 \%$ SDS, and $\left[{ }^{3} \mathrm{H}\right] \mathrm{L}$-tryptophan $/\left[{ }^{3} \mathrm{H}\right] \mathrm{L}$-glutamine uptake was determined by liquid scintillation. 


\section{CRISPR-Cas9-mediated gene silencing}

CRISPR-Cas9 technology was used to silence SLC1A5 and ATF4 by targeting unique sequences in the coding region of exon 4 and exon 1, respectively. Cas 9 and the chimeric guide RNA were delivered to WT HeLa cells using the lentiCRISPRv2 construct (Addgene plasmid \#52961).

\section{Analysis of mRNA expression in primary human tumors}

Expression of mRNA measured by RNA sequencing was downloaded from the TCGA data portal for LIHC ( $\mathrm{n}=374)$, OV ( $\mathrm{n}=309)$, GBM $(\mathrm{n}=169), \mathrm{LGG}(\mathrm{n}=534), \mathrm{UCEC}(\mathrm{n}=177)$, ACC $(n=79)$, CESC $(n=306)$, BRCA $(n=1102)$, and KIRC $(n=534)$, and the Spearman's rank correlation coefficient was calculated between the expressions of SLC1A5 and WARS, TDO2, IDO1, and ATF4 for each tumor type. Additionally, clinical data was downloaded for the LGG samples, and Kaplan-Meier curves comparing survival of patients with low and high expression of SLC1A5, IDO1, and the combinations thereof were made. Statistical analysis was performed using log-rank test.

\section{Statistical analysis}

Statistical analysis was performed using Prism software (GraphPad, San Diego, CA). Unpaired, two-tailed Student's t-test was used to determine statistical significance, unless indicated otherwise. The threshold for rejection of the null hypothesis was $p<0.05$. 


\section{Results}

\section{Tumor cells expressing tryptophan-catabolizing enzymes up-regulate the expression}

\section{of several amino acid transporter genes}

To investigate the effect of IDO activity on tumor cell whole transcriptome profile, we developed an in vitro system where IDO expression was induced either by transducing HeLa cells with a lentivirus encoding human IDO (IDO ${ }^{+} \mathrm{HeLa}$ ) (12) or by treating HeLa cells with IFN $\gamma$ (IFN $\gamma$ HeLa). We confirmed that IDO was biologically active by measuring the kynurenine-to-tryptophan ratio in the supernatants obtained from $\mathrm{IDO}^{+}$and IFN $\gamma \mathrm{HeLa}$ cells, as compared to HeLa cells transduced with a lentivirus encoding GFP (GFP HeLa) or untreated wild-type (WT) HeLa cells (Fig. S1A). Using this system we identified the genes modulated in $\mathrm{IDO}^{+} \mathrm{HeLa}$ cells under conditions of nutritional stress caused by incubation in limited amount of culture medium, and compared them with the gene profiling of IFN $\gamma$ HeLa cells by RNA-seq (GSE75956). After $72 \mathrm{~h}$ of culture, $\mathrm{IDO}^{+} \mathrm{HeLa}$ cells up-regulated several genes that were also up-regulated in IFN $\gamma$ HeLa cells (Fig. 1A). Such shared genetic signature between IDO $^{+} \mathrm{HeLa}$ and IFN $\gamma$ HeLa cells was more evident at $72 \mathrm{~h}$ rather than at 48 h (Fig. 1B), which could be accounted for by differences in the kinetics required by $\mathrm{IDO}^{+} \mathrm{HeLa}$ cells to degrade tryptophan contained in the culture medium. At $72 \mathrm{~h}$, this shared transcriptional signature included the expression of genes involved in the regulation of cellular redox signaling and apoptosis (such as TXNIP (15)), t-RNA amino acylation, glutamine/glutamate and monosaccharide metabolism, and amino acid and carboxylic acid biosynthesis and transport, among other functions (Fig. 1A). The most abundantly upregulated gene involved in t-RNA amino acylation was tryptophanyl-tRNA synthetase (WARS), while the most abundantly up-regulated genes associated with amino acid transport were SLC7A11 (cystine/glutamate exchanger), SLC1A4 (glutamate/neutral amino acid transporter), SLC1A5 (glutamine/neutral amino acid transporter) and, to a lesser extent, 
SLC6A9 (glycine neurotransmitter transporter) (Fig. 1A and B). Other major amino acid transporters, including CD98 heavy chain (SLC3A2) and LAT1 (SLC7A5) showed a less pronounced differential expression in HeLa cells expressing IDO (Fig. 1B). Notably, out of the top four up-regulated SLC genes, SLC1A5 was the only transporter associated with EAA transport (16) and tryptophan transport network, as determined using the MetaCore pathway analysis software (Fig. S1B).

Further analysis demonstrated that, in addition to the full-length SLC1A5 transcript, hereafter referred to as $S L C 1 A 5$ long $(S L C 1 A 5(L))$, there were truncated splice variants of SLC1A5 - SLC1A5 middle (SLC1A5(M)) and SLC1A5 short (SLC1A5(S)) (Fig. S1C). We utilized the unique sequences in the non-coding regions of the SLC1A5(S) and SLC1A5(M) transcripts to design a quantitative PCR assay for specific amplification of $\operatorname{SLC1A5}(L)$, SLC1A5(S) and SLC1A5(M) mRNA. IFN $\gamma$-treated WT, IDO1-transduced HeLa, as well as HeLa cells overexpressing the tryptophan-degrading enzyme TDO exhibited increased expression of all three SLC1A5 variants (Fig. 1C). In agreement with the RNA-seq data, Real-Time PCR analysis of transcripts associated with SLC7A11 and SLC1A4 confirmed their up-regulation in IDO- and TDO-expressing HeLa cells (Fig. 1C).

Next, we assessed SLC1A5 protein expression in tumor cells exhibiting IDO or TDO activity using an antibody specific for the N-terminus of the full length SLC1A5, which is expected to detect SLC1A5(L) but not the other isoforms. SLC1A5 expression levels increased substantially in tumor cells treated with IFN $\gamma$ and those transduced with IDO or TDO (Fig. 1D).

To validate that tumor cells overexpressing SLC1A5 are able to up-regulate their amino acid uptake, we overexpressed SLC1A5(L) and its most truncated isoform, SLC1A5(S), in HeLa cells. Since SLC1A5 has been reported to have high affinity for glutamine $(13,14,17)$, we first examined the capacity of transduced cells to transport radiolabeled 
glutamine $\left(\left[{ }^{3} \mathrm{H}\right] \mathrm{Gln}\right)$. As expected, we observed higher levels of radiolabeled glutamine uptake in SLC1A5(L)-transduced tumor cells than in those expressing endogenous levels of this transporter (Fig. 2A). Notably, glutamine uptake capacity was also increased in tumor cells overexpressing SLC1A5(S) (Fig. 2A). Consistently with the reported $\mathrm{Na}^{+}$-dependency of SLC1A5 $(13,14), \operatorname{SLC1A5}(L)$ - and SLC1A5(S)-transduced tumor cells failed to upregulate glutamine uptake under $\mathrm{Na}^{+}$-free conditions (data not shown). Furthermore, treatment of both transduced and control tumor cells with a characterized pharmacological inhibitor of SLC1A5 O-Benzyl-L-serine (BenSer) $(18,19)$ reduced glutamine uptake in a dose-dependent manner (Fig. 2A).

Next, we assessed the action of SLC1A5 on radiolabeled tryptophan $\left(\left[{ }^{3} \mathrm{H}\right] \mathrm{Trp}\right)$ uptake. Overexpression of SLC1A5(L), and particularly of SLC1A5(S) in HeLa cells, improved their tryptophan uptake capacity (Fig. 2B). Conversely, radiolabeled tryptophan transport was reduced in the presence of SLC1A5 pharmacological inhibitor BenSer (Fig. 2C). In line with these findings, BenSer treatment also reduced mTOR activation in HeLa cells (Fig. S2A). Furthermore, SLC1A5 knockdown resulted in a significant impairment of HeLa cell proliferation under amino acid sufficient conditions (Fig. S2B and C). This effect was enhanced even further following tryptophan withdrawal (Fig. S2C).

Although not reported to transport tryptophan directly $(13,17)$, SLC1A5 has been proposed to facilitate the activity of the dominant neutral amino acid transporter LAT1 (SLC7A5) (20) through bidirectional transport (16). Consistent with this model, we found that tryptophan uptake in HeLa cells is heavily dependent on LAT1 activity, as evidenced by the abolished radiolabeled tryptophan transport into tumor cells lacking LAT1 (Fig. S2D and $\mathbf{E})$.

Collectively, these findings demonstrate for the first time the association between tryptophan catabolism and modulation of metabolic and amino acid transporter profiling in 
tumor cells. In particular, we show that increased expression levels of SLC1A5 isoforms lead to improved transport of glutamine and tryptophan into tumor cells.

\section{Tryptophan-starved tumor cells up-regulate SLC1A5 expression}

Since IDO activity converts tryptophan into kynurenine, we speculated that up-regulation of SLC1A5 in $\mathrm{IDO}^{+}$tumor cells could be accounted for by the reduced concentration of tryptophan in the culture medium. Alternatively, it may be due to accumulation of tryptophan metabolite kynurenine, which has been identified as an endogenous ligand of the human aryl hydrocarbon receptor (AhR) (4). To distinguish between these two possibilities, we exposed WT HeLa cells, exhibiting no IDO or TDO activity, either to tryptophan-deficient conditions or to increasing concentrations of AhR agonists kynurenine and 6-formylindolo[3,2-b]carbazole (FICZ), and measured their SLC1A5 expression. While AhR agonists had no effect on the levels of SLC1 A5 expression (Fig. S3), WT HeLa cells incubated in the culture medium depleted of tryptophan up-regulated SLC1A5 (Fig.

3A and B). This effect was observable at concentrations of tryptophan equal to or below $5 \mu \mathrm{M}$ (Fig. 3B), and was abolished at the concentration of $10 \mu \mathrm{M}$ or higher, which we confirmed both at the mRNA and protein level (Fig. 3A and B). Importantly, we extended the results obtained in HeLa cells to a panel of other human tumor cell lines, including epidermoid carcinoma, prostate and pancreas cancer cell lines (Fig. 3C), demonstrating that the mechanisms controlling SLC1A5 up-regulation are shared by a range of tumor cell lines of different origin.

Having established that shortage of tryptophan can up-regulate SLC1A5, we decided to extend these results by assessing whether the lack of other amino acids could also have an effect on this transporter's expression in tumor cells. Incubation of WT HeLa cells in the culture medium depleted of glutamine or arginine markedly increased their SLC1A5 
expression, while this induction was less profound in the absence of leucine or isoleucine (Fig. 3D). Glycine or serine deprivation, on the other hand, exerted no effect on SLC1A5 expression (Fig. 3D). Interestingly, tryptophan depletion, in addition to up-regulation of SLC1A5, also increased expression of SLC7A11 and SLC1A4 (Fig. 4G), demonstrating a more general effect of tryptophan catabolism on the amino acid transporter profiling.

Collectively, these findings show that SLC1A5 expression is regulated by amino acid availability and demonstrate its sensitivity to variation in the local tryptophan concentration.

\section{SLC1A5 up-regulation in tryptophan-starved tumor cells is dependent on the ATF4}

\section{pathway}

We next assessed the possible mechanisms that may account for the induction of SLC1A5 during tryptophan starvation. Amino acid depletion is sensed by the ATF4 pathway, which can be activated in response to increased levels of uncharged tRNA (7). We interrogated our RNA-seq data for changes in the expression of stress response genes in $\mathrm{IDO}^{+}$tumor cells, and observed a strong transcriptional signature associated with ATF4 pathway activation, as evidenced by the up-regulation of ATF4, ATF3, CHOP, GADD34, TRIB3 and HERPUD1 genes in IFN $\gamma$-treated WT and IDO1-transduced HeLa cells (Fig. 4A and B). In line with the reported role of ATF4 in autophagy regulation (21), tumor cells exposed to tryptophan deprivation also exhibited increased autophagy levels, as determined by elevated LC3-II to LC3-I ratio (Fig. S4).

To investigate whether ATF4 expression is differentially modulated by the absence of distinct amino acids, we measured ATF4 levels in WT HeLa cells cultured under various amino acid-deprived conditions. While ATF4 protein was almost undetectable in complete medium, its expression increased markedly in tumor cells cultured in the absence of 
tryptophan, glutamine, and, to a lesser extent, arginine and isoleucine (Fig. 4C). Lack of glycine and serine, on the other hand, failed to activate ATF4 in HeLa cells (Fig. 4C). Furthermore, similarly to SLC1A5, ATF4 expression was induced by concentrations of tryptophan lower than $5 \mu \mathrm{M}$, as ATF4 could not be detected after supplementing the culture medium with $10 \mu \mathrm{M}$ tryptophan (Fig. 4D). We thus demonstrated that ATF4 expression in starved tumor cells mirrors that of SLC1A5.

To determine the role of the ATF4 pathway in regulation of SLC1A5 expression under tryptophan-deficient conditions, we knocked down ATF4 from HeLa cells using a lentiviral CRISPR construct (Table S1). In contrast to WT tumor cells, no SLC1A5 up-regulation could be detected in ATF4 knockdown tumor cells under culture conditions lacking tryptophan (Fig. 4E). We confirmed these results using ATF4 shRNA knockdown strategy

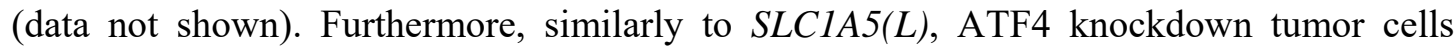
failed to up-regulate transcription of truncated SLC1A5 isoforms following tryptophan withdrawal (Fig. 4F), underscoring that SLC1A5 isoform induction in tryptophan-starved tumor cells is also controlled by the ATF4 pathway. Similarly, we showed that upregulation of SLC7A11 and SLC1A4 in tryptophan-depleted medium was abolished in ATF4 knockdown cells (Fig. 4G).

Collectively, these findings demonstrate the role of ATF4 in modulating the changes in amino acid transporter profiling under culture conditions with reduced concentrations of tryptophan.

\section{SLC1 A5 expression in human $T$ cells is unaffected by tryptophan starvation}

Tryptophan degradation by IDO-expressing tumors is a common mechanism of immune escape, which inhibits effector $\mathrm{T}$ cells $(1,3)$. We (12) and others $(10,11,22)$ have demonstrated that $\mathrm{T}$ cell exposure to tryptophan-depleted microenvironment induces their 
proliferative arrest. To determine whether T lymphocytes are able to alter their SLC1A5 expression profile when undergoing tryptophan starvation, we incubated resting or activated human $\mathrm{CD}^{+}$and $\mathrm{CD} 8^{+} \mathrm{T}$ cells in tryptophan-depleted medium. While resting $\mathrm{T}$ cells hardly exhibited any detectable levels of SLC1A5, treatment with $\alpha \mathrm{CD} 3 / \mathrm{CD} 28$ antibodies readily up-regulated SLC1A5 expression (Fig. 5A), which is consistent with the increased metabolic demands of activated $\mathrm{T}$ cells (23). In line with these results, pharmacological inhibition of SLC1A5 reduced mTOR activation in stimulated $\mathrm{T}$ cells (Fig. S5A).

Surprisingly, in sharp contrast to the up-regulation of SLC1A5 observed in a panel of tumor cell lines maintained under identical conditions, resting $\mathrm{CD}^{+}$and $\mathrm{CD}^{+} \mathrm{T}$ cells failed to enhance SLC1A5 expression in response to tryptophan depletion (Fig. 5A and B). Moreover, while incubation of $\mathrm{T}$ cells with $\alpha \mathrm{CD} 3 / \mathrm{CD} 28$ antibodies led to increased SLC1A5 expression, tryptophan depletion of $\alpha \mathrm{CD} 3 / \mathrm{CD} 28$-treated $\mathrm{T}$ cells failed to induce further up-regulation of SLC1A5, in the face of ATF4 activation (Fig. 5A). Human T cells kept in tryptophan-depleted medium also failed to express the alternative SLC1A5 isoform (Fig. 5B). Notably, although $\mathrm{T}$ cells increased the levels of SLC1A5 expression upon stimulation, this up-regulation was not sufficient to facilitate levels of tryptophan uptake comparable to those observed in tumor cells (Fig. S5B).

Furthermore, in contrast to tumor cells, tryptophan-starved T cells also failed to up-regulate tryptophanyl-tRNA synthetase WARS, while its expression, similarly to that of SLC1A5, was enhanced upon $\mathrm{T}$ cell activation (Fig. S5C). These findings highlight differential regulation of ATF4-dependent genes controlling compensatory mechanisms triggered by the shortage of tryptophan in tumor and T cells.

Up-regulation of SLC1A5 in $\alpha \mathrm{CD} 3 / \mathrm{CD} 28$-treated $\mathrm{T}$ cells is consistent with the increased metabolic demand of activated $\mathrm{T}$ cells for amino acids such as glutamine $(24,25)$. 
However, it remains unclear whether up-regulation of SLC1A5 upon T cell receptor (TCR)-dependent $\mathrm{T}$ cell activation can be modulated by the strength of the TCR signaling events. To address this question, we stimulated an NY-ESO-1-specific human $\mathrm{CD}^{+} \mathrm{T}$ cell clone with increasing concentrations of the cognate NY-ESO-1 $1_{157-165}$ peptide (26) or with $\alpha \mathrm{CD} 3 / \mathrm{CD} 28$ antibodies, as a control. We then used the previously characterized SLC1A5specific staining reagent (27), which utilizes the binding specificity of the RD114 virus envelope glycoprotein for this amino acid transporter (28), to correlate SLC1A5 surface expression with $\mathrm{T}$ cell activation, as defined by CD25 up-regulation. We observed that upregulation of SLC1A5 directly correlated with the amount of NY-ESO-1 $1_{157-165}$ peptide added (Fig. 5C) and with CD25 up-regulation (data not shown).

Collectively, these findings demonstrate that SLC1A5 expression in human T cells is dependent on the strength of TCR engagement. However, unlike human tumor cell lines, resting and activated $\mathrm{CD}^{+}$and $\mathrm{CD}^{+} \mathrm{T}$ cells fail to up-regulate $\mathrm{SLC} 1 \mathrm{~A} 5$ in response to tryptophan starvation. These results highlight a key difference in the ability of tumor cells and T lymphocytes to adapt to tryptophan starvation.

\section{SLC1A5 and IDO co-expression is observed in several primary human tumors and is} associated with poor survival in brain lower grade glioma

Having identified the relationship between IDO/TDO-induced tryptophan depletion and SLC1A5 up-regulation in human tumor cell lines, we next tested whether IDO-expressing tumors up-regulate SLC1A5 expression in vivo. To address this question, we injected IDOexpressing or IDO negative mouse EG7 GFP thymoma cells into B6.SJL-Ptprc ${ }^{\mathrm{a}}$ mice and assessed SLC1A5 transcription after 5 days of in vivo growth. Although when kept in normal tissue culture medium EG7 GFP IDO and EG7 GFP cells had similar transcription levels of SLC1A5 (data not shown), upon in vivo injection EG7 GFP IDO tumors exhibited 
significantly higher levels of SLC1A5 expression than the IDO negative EG7 GFP tumors (Fig. S6A).

We then investigated whether the association between tryptophan catabolism and SLC1A5 expression can be observed in primary human tumor samples. In line with regulation of SLC1A5 expression by the ATF4 pathway, our in silico analysis of available RNA-seq data demonstrated that in a large proportion of human tumors, SLC1A5 positively correlates with ATF4 expression (Fig. 6A). However, since ATF4 activation can occur in response to several stresses, including hypoxia/anoxia and nutrient deprivation (29), we assessed whether co-expression of SLC1A5 and ATF4 correlated with the up-regulation of genes more relevant to catabolism of tryptophan in particular, such as tryptophanyl-tRNA synthetase WARS, which we have previously shown to be up-regulated in IDO-expressing and tryptophan-starved HeLa cells (Fig. 1A, 1B and S5C). The results of this analysis demonstrated a strong positive correlation between SLC1A5 and WARS expression in several tumors, particularly human liver hepatocellular carcinoma, ovarian serous cystadenocarcinoma, glioblastoma multiforme and brain lower grade glioma (Fig. 6A). Importantly, in these tumor types SLC1A5 also correlated significantly with the expression of one or both of the tryptophan-degrading enzyme-encoding genes IDO1 and TDO2 (Fig. 6A), hence supporting our in vitro data describing the tryptophan shortage-induced SLC1A5 up-regulation in $\mathrm{IDO}^{+}$and $\mathrm{TDO}^{+}$tumor cell lines.

We next assessed the significance of SLC1A5 and IDO1 tumor expression for patient prognosis. We found that, in brain lower grade glioma, which exhibited a particularly strong positive correlation between SLC1A5 and IDO1 expression (Fig. 6A), high expression of SLC1A5 was significantly associated with decreased patient survival (Hazard ratio $=0.40526$; log-rank test $p$-value $=0.00006)$ (Fig. 6B). We also observed a similar association between survival and high IDO1 expression in this tumor type (Hazard 
ratio $=0.46179$; log-rank test p-value $=0.00053)$ (Fig. 6C). Furthermore, patients with $I D O^{h i} S L C 1 A 5^{l o}$ lower grade gliomas survived significantly longer than those with $I D O^{h i} S L C 1 A 5^{h i}$ tumors (Hazard ratio=0.49285; log-rank test p-value=0.01564), while $I D O^{l o} S L C 1 A 5^{l o}$ tumors correlated with best prognosis (Fig. 6D and S6B).

These data highlight the clinical importance of IDO and SLC1A5 up-regulation by human tumors such as brain lower grade glioma, and suggest their potential use as prognostic biomarkers. Research. 


\section{Discussion}

In this study, we showed that IDO activity induces extensive remodeling of tumor cells' amino acid metabolism gene expression and alters the expression of the amino acid transporter-encoding genes SLC7A11, SLC1A4 and SLC1A5, including two novel SLC1A5 splice variants. Such changes in the amino acid transporter profiling of IDO-expressing tumor cells are induced by shortage of tryptophan, rather than accumulation of kynurenine, and are dependent on the activation of the transcription factor ATF4 - a master regulator of numerous stress response genes, including tryptophanyl-tRNA synthetase (WARS) $(8,30)$. Up-regulation of SLC1A5 (and its splice variants), in addition to enhancing the uptake of glutamine, also improves tryptophan transport, which can be blocked by the SLC1A5specific inhibitor BenSer $(18,19)$ or by deleting expression of LAT1 (SLC7A5) (20) - a component of the ubiquitous amino acid transporter System L, which constitutes the major neutral amino acid transport system, importing large hydrophobic amino acids with branched or aromatic side chains, such as leucine and tryptophan (31). Being an obligate amino acid exchanger, LAT1 activity depends largely on the exchange of intracellular glutamine for EAAs (16). Our results describing the abolishment of tryptophan uptake in LAT1 knockout tumor cells are consistent with the above data demonstrating that SLC1A5dependent glutamine efflux facilitates EAA uptake by activating System L bi-directional transport mechanisms (16).

Previous results have implicated SLC1A5, which, similarly to SLC7A5, is highly expressed in several human cancers (32), in promoting tumor cell growth and survival. The antiproliferative effect of targeting SLC1A5 has been demonstrated in various tumor types $(18,33-40)$. We have extended these findings by demonstrating a role for SLC1A5 in tumor cell proliferation not only under amino acid sufficient but also tryptophan starvation conditions. These results are consistent with the hypothesis that SLC1A5-mediated amino 
acid uptake acts as a compensatory mechanism to facilitate proliferation of $\mathrm{IDO}^{+}$cancer cells under low tryptophan conditions. However, we cannot rule out the alternative hypothesis that SLC1A5 co-operates with IDO to facilitate increased influx of tryptophan, thus ensuring its further deprivation from the tumor microenvironment through IDOdependent degradation. Additional experiments to address this possibility, as well as the involvement of other potentially important tryptophan shortage compensatory mechanisms, such as WARS-mediated tryptophanyl-tRNA stock repletion, are warranted.

The mechanisms underlying regulation of glutamine transporters such as SLC1A5 in cancer are largely poorly understood. While we have demonstrated that SLC1A5 isoform induction in IDO- and TDO-expressing tumor cells is a direct consequence of tryptophan depletion, we have also observed differential modulation of SLC1A5 expression by the withdrawal of distinct amino acids from the culture medium. These results are consistent with SLC1A5 up-regulation representing a specific amino acid depletion response mechanism. Importantly, we established that concentrations of tryptophan ranging from $0 \mu \mathrm{M}$ to $5 \mu \mathrm{M}$ enhance SLC1A5 expression. Since tryptophan concentrations below $5 \mu \mathrm{M}$ induce $\mathrm{T}$ cell proliferative arrest (22), our findings indicate a coordinated cancer immune evasion mechanism designed to inhibit $\mathrm{T}$ cell proliferation, while simultaneously upregulating compensatory signaling events in cancer cells.

ATF4 is a known regulator of the nutritional stress response $(7,8)$, which we showed to be up-regulated in IDO-expressing tumor cells and, importantly, to be activated upon exposure of tumor cells to culture conditions with limited amounts of tryptophan. Notably, all three top up-regulated transporters in $\mathrm{IDO}^{+}$tumor cells showed evidence of regulation by the ATF4 pathway. These data are in agreement with the previously reported regulation of several amino acid transporter genes by the ATF4 pathway $(8,37)$ and with the role of ATF4 in promoting tumor cells' survival and proliferation under amino acid starvation 
conditions (41). Our results highlight the importance of the ATF4 stress response pathway for sustaining metabolic homeostasis in tumor cells exposed to tryptophan deprivation and identify it as a potential target for treatment of $\mathrm{IDO}^{+}$and $\mathrm{TDO}^{+}$tumors. Other pathways have also been reported to regulate SLC1A5 expression, including c-Myc (42), N-Myc (37), Rb/E2F (43), EGF signaling (44), and RNF5 (45). These cell intrinsic mechanisms, linked to the neoplastic process, could synergize with the environmental effect of tryptophan depletion and may prove to be important therapeutic targets.

The immunosuppressive effects of tryptophan catabolism on $\mathrm{T}$ cells have been welldocumented $(1,10,12,22)$, and the involvement of the GCN2-ATF4 pathway has been proposed (10). However, very little is known about the effects of ATF4 pathway activation on the amino acid transporter expression profile in $\mathrm{T}$ cells. It is clear that stimulated $\mathrm{T}$ cells undergo extensive metabolic reprogramming to meet the increased energetic and biosynthetic demands of proliferating cells. This is reflected in the switch to anaerobic glycolysis (23) and enhanced ability of activated T cells to transport amino acids like phenylalanine, leucine and glutamine $(24,25,46)$. Furthermore, $\mathrm{T}$ cell activation is associated with up-regulation of several amino acid transporters, including SLC7A5 (LAT1), SLC3A2 (CD98hc), as well as glutamine transporters SLC38A1 (SNAT1), SLC38A2 (SNAT2) and SLC1A5 $(24,46)$. Consistent with these findings, we observed enhanced expression of SLC1A5 in human $\mathrm{CD}^{+}$and $\mathrm{CD}^{+} \mathrm{T}$ cells treated with $\alpha \mathrm{CD} 3 / \mathrm{CD} 28$ antibodies, and demonstrated the modulation of SLC1A5 up-regulation by the strength of TCR engagement.

The dichotomy between tumor cells and T cells in their ability to up-regulate SLC1A5 in a tryptophan low microenvironment is of importance. Consistent with previous findings (10), we detected activation of the ATF4 pathway in activated T cells. Strikingly, however, although $\mathrm{T}$ cells were able to up-regulate SLC1A5 in response to $\alpha \mathrm{CD} 3 / \mathrm{CD} 28$ treatment, 
which has been previously shown to be mediated by CARMA1 (25), they failed to increase the levels of this transporter following tryptophan withdrawal, irrespectively of their activation status. Tumor cell lines, on the other hand, readily up-regulated SLC1A5 under these conditions, which was coupled to robust ATF4 expression. A scenario where ATF4 binding to the C/EBP-ATF composite site of the target gene occurs without stimulation of transcriptional activity has been reported for SLC38A2 (SNAT2) transporter (47). The authors describe a repressive signal downstream of ATF4 binding to SNAT2 promoter, which inhibits SNAT2 transcription in response to the unfolded protein response. We speculate that a similar mechanism may account for the lack of SLC1A5 up-regulation in tryptophan-starved $\mathrm{T}$ cells. It would be insightful to compare the epigenetic landscape of SLC1A5 promoter following tryptophan deficiency-induced ATF4 activation in tumor cells and $\mathrm{T}$ cells.

In a tumor microenvironment where essential nutrients are restricted, cancer and immune cells' capacity for metabolic reprogramming may play a crucial role in the fate of tumor progression. In line with this, we found that the strong positive correlation between SLC1A5 and IDO1 expression in brain lower grade glioma is significantly associated with decreased patient survival. This observation is clinically important, as it suggests the potential use of SLC1A5 and IDO1 expression as prognostic biomarkers, and provides therapeutic opportunities. Our observations complement previous studies, which have proposed high SLC1A5 expression as a marker of poor prognosis in MYCN-driven neuroblastoma (37), non-small cell lung cancer (35) and breast cancer (45).

In conclusion, we have described that in tumor cells, shortage of tryptophan induced by the expression of tryptophan-degrading enzymes initiates ATF4-dependent reprogramming of several amino acid transporter gene expression, including SLC1A5 and its truncated isoforms, which allows improved glutamine and tryptophan import into tumor cells. 
Notably, this strategy is not shared by resting human $\mathrm{T}$ cells, which provides important insights into the mechanisms by which cancer cells but not tumor-infiltrating $\mathrm{T}$ cells can compensate for the shortage of tryptophan in the local microenvironment. Finally, IDO and SLC1A5 tumor expression can have significant clinical implications, as demonstrated by the decreased survival associated with IDO $^{\text {hi }} \mathrm{SLC} 1 \mathrm{~A} 5^{\text {hi }}$ brain lower grade gliomas. Our studies shed light on the compensatory mechanisms employed by tumors to allow survival under conditions of nutritional stress and have relevance for the identification of novel targets for pharmacological inhibition of tumors expressing amino acid-degrading enzymes IDO and TDO. 
Author Manuscript Published OnlineFirst on September 20, 2016; DOI: 10.1158/0008-5472.CAN-15-3502

Author manuscripts have been peer reviewed and accepted for publication but have not yet been edited.

\section{Acknowledgments}

We thank Adrian Harris, Ji-Li Chen, Mariolina Salio, Giorgio Napolitani, Craig Waugh,

Kevin Clark, Margarida Rei, Helio Pais and Joey Riepsaame (WIMM, Oxford) for their help and assistance. Research. 


\section{References}

1. Uyttenhove C, Pilotte L, Theate I, Stroobant V, Colau D, Parmentier N, et al. Evidence for a tumoral immune resistance mechanism based on tryptophan degradation by indoleamine 2,3-dioxygenase. Nature Medicine 2003;9(10):1269-74.

2. Theate I, van Baren N, Pilotte L, Moulin P, Larrieu P, Renauld J-C, et al. Extensive Profiling of the Expression of the Indoleamine 2,3-Dioxygenase 1 Protein in Normal and Tumoral Human Tissues. Cancer Immunology Research 2015;3(2):161-72.

3. Pilotte L, Larrieu P, Stroobant V, Colau D, Dolusic E, Frederick R, et al. Reversal of tumoral immune resistance by inhibition of tryptophan 2,3-dioxygenase. Proc Natl Acad Sci U S A 2012;109(7):2497-502.

4. Opitz CA, Litzenburger UM, Sahm F, Ott M, Tritschler I, Trump S, et al. An endogenous tumour-promoting ligand of the human aryl hydrocarbon receptor. Nature 2011;478(7368):197-203.

5. Godin-Ethier J, Hanafi L-A, Piccirillo CA, Lapointe R. Indoleamine 2,3Dioxygenase Expression in Human Cancers: Clinical and Immunologic Perspectives. Clinical Cancer Research 2011;17(22):6985-91.

6. Holmgaard RB, Zamarin D, Munn DH, Wolchok JD, Allison JP. Indoleamine 2,3dioxygenase is a critical resistance mechanism in antitumor $\mathrm{T}$ cell immunotherapy targeting CTLA-4. Journal of Experimental Medicine 2013;210(7):1389-402.

7. Harding HP, Novoa I, Zhang YH, Zeng HQ, Wek R, Schapira M, et al. Regulated translation initiation controls stress-induced gene expression in mammalian cells. Mol Cell 2000;6(5):1099-108. 
8. Harding HP, Zhang YH, Zeng HQ, Novoa I, Lu PD, Calfon M, et al. An integrated stress response regulates amino acid metabolism and resistance to oxidative stress. Mol Cell 2003;11(3):619-33.

9. Kilberg MS, Pan YX, Chen H, Leung-Pineda V. Nutritional control of gene expression: How mammalian cells respond to amino acid limitation. Annual Review of Nutrition 2005;25:59-85.

10. Munn DH, Sharma MD, Baban B, Harding HP, Zhang YH, Ron D, et al. GCN2 kinase in $\mathrm{T}$ cells mediates proliferative arrest and anergy induction in response to indoleamine 2,3-dioxygenase. Immunity 2005;22(5):633-42.

11. Munn DH, Shafizadeh E, Attwood JT, Bondarev I, Pashine A, Mellor AL. Inhibition of $\mathrm{T}$ cell proliferation by macrophage tryptophan catabolism. Journal of Experimental Medicine 1999;189(9):1363-72.

12. Silk JD, Lakhal S, Laynes R, Vallius L, Karydis I, Marcea C, et al. IDO Induces Expression of a Novel Tryptophan Transporter in Mouse and Human Tumor Cells. Journal of Immunology 2011;187(4):1617-25.

13. Kekuda R, Prasad PD, Fei YJ, TorresZamorano V, Sinha S, YangFeng TL, et al. Cloning of the sodium-dependent, broad-scope, neutral amino acid transporter B-O from a human placental choriocarcinoma cell line. Journal of Biological Chemistry 1996;271(31):18657-61.

14. Utsunomiya-Tate N, Endou H, Kanai Y. Cloning and functional characterization of a system ASC-like Na+-dependent neutral amino acid transporter. Journal of Biological Chemistry 1996;271(25):14883-90.

15. Spindel ON, World C, Berk BC. Thioredoxin Interacting Protein: Redox Dependent and Independent Regulatory Mechanisms. Antioxidants \& Redox Signaling 2012;16(6):587-96. 
16. Nicklin P, Bergman P, Zhang B, Triantafellow E, Wang H, Nyfeler B, et al. Bidirectional Transport of Amino Acids Regulates mTOR and Autophagy. Cell 2009;136(3):521-34.

17. Pingitore P, Pochini L, Scalise M, Galluccio M, Hedfalk K, Indiveri C. Large scale production of the active human ASCT2 (SLC1A5) transporter in Pichia pastoris functional and kinetic asymmetry revealed in proteoliposomes. Biochimica Et Biophysica Acta-Biomembranes 2013;1828(9):2238-46.

18. Wang Q, Beaumont KA, Otte NJ, Font J, Bailey CG, van Geldermalsen M, et al. Targeting glutamine transport to suppress melanoma cell growth. International Journal of Cancer 2014;135(5):1060-71.

19. Grewer C, Grabsch E. New inhibitors for the neutral amino acid transporter ASCT2 reveal its Na+-dependent anion leak. Journal of Physiology 2004;557(3):747-59.

20. Kanai Y, Segawa H, Miyamoto K, Uchino H, Takeda E, Endou H. Expression cloning and characterization of a transporter for large neutral amino acids activated by the heavy chain of 4F2 antigen (CD98). Journal of Biological Chemistry 1998;273(37):23629-32.

21. B'Chir W, Maurin A-C, Carraro V, Averous J, Jousse C, Muranishi Y, et al. The eIF2 alpha/ATF4 pathway is essential for stress-induced autophagy gene expression. Nucleic Acids Research 2013;41(16):7683-99.

22. Kudo Y, Boyd CAR, Sargent IL, Redman CWG. Tryptophan degradation by human placental indoleamine 2,3-dioxygenase regulates lymphocyte proliferation. Journal of Physiology 2001;535(1):207-15.

23. MacIver NJ, Michalek RD, Rathmell JC. Metabolic Regulation of T Lymphocytes. Annual Review of Immunology 2013;31:259-83. 
24. Carr EL, Kelman A, Wu GS, Gopaul R, Senkevitch E, Aghvanyan A, et al. Glutamine Uptake and Metabolism Are Coordinately Regulated by ERK/MAPK during T Lymphocyte Activation. Journal of Immunology 2010;185(2):1037-44.

25. Nakaya M, Xiao Y, Zhou X, Chang J-H, Chang M, Cheng X, et al. Inflammatory T Cell Responses Rely on Amino Acid Transporter ASCT2 Facilitation of Glutamine Uptake and mTORC1 Kinase Activation. Immunity 2014;40(5):692-705.

26. Chen JL, Dunbar PR, Gileadi U, Jager E, Gnjatic S, Nagata Y, et al. Identification of NY-ESO-1 peptide analogues capable of improved stimulation of tumor-reactive CTL. Journal of Immunology 2000;165(2):948-55.

27. Laval J, Touhami J, Herzenberg LA, Conrad C, Taylor N, Battini J-L, et al. Metabolic Adaptation of Neutrophils in Cystic Fibrosis Airways Involves Distinct Shifts in Nutrient Transporter Expression. Journal of Immunology 2013;190(12):6043-50.

28. Rasko JEJ, Battini JL, Gottschalk RJ, Mazo I, Miller AD. The RD114 simian type D retrovirus receptor is a neutral amino acid transporter. Proc Natl Acad Sci U S A 1999;96(5):2129-34.

29. Ameri K, Harris AL. Activating transcription factor 4. International Journal of Biochemistry \& Cell Biology 2008;40(1):14-21.

30. Han J, Backa SH, Hur J, Lin Y-H, Gildersleeve R, Shan J, et al. ER-stress-induced transcriptional regulation increases protein synthesis leading to cell death. Nature Cell Biology 2013;15(5):481-90.

31. Verrey F. System L: heteromeric exchangers of large, neutral amino acids involved in directional transport. Pflugers Archiv-European Journal of Physiology 2003;445(5):529-33. 
32. Fuchs BC, Bode BP. Amino acid transporters ASCT2 and LAT1 in cancer: Partners in crime? Seminars in Cancer Biology 2005;15(4):254-66.

33. Fuchs BC, Finger RE, Onan MC, Bode BP. ASCT2 silencing regulates mammalian target-of-rapamycin growth and survival signaling in human hepatoma cells. American Journal of Physiology-Cell Physiology 2007;293(1):C55-C63.

34. Hassanein M, Hoeksema MD, Shiota M, Qian J, Harris BK, Chen H, et al. SLC1A5 Mediates Glutamine Transport Required for Lung Cancer Cell Growth and Survival. Clinical Cancer Research 2013;19(3):560-70.

35. Hassanein M, Qian J, Hoeksema MD, Wang J, Jacobovitz M, Ji X, et al. Targeting SLC1a5-mediated glutamine dependence in non-small cell lung cancer. International Journal of Cancer 2015;137(7):1587-97.

36. Willems L, Jacque N, Jacquel A, Neveux N, Maciel TT, Lambert M, et al. Inhibiting glutamine uptake represents an attractive new strategy for treating acute myeloid leukemia. Blood 2013;122(20):3521-32.

37. Ren P, Yue M, Xiao D, Xiu R, Gan L, Liu H, et al. ATF4 and N-Myc coordinate glutamine metabolism in MYCN-amplified neuroblastoma cells through ASCT2 activation. Journal of Pathology 2015;235(1):90-100.

38. Huang F, Zhao Y, Zhao J, Wu S, Jiang Y, Ma H, et al. Upregulated SLC1A5 promotes cell growth and survival in colorectal cancer. International Journal of Clinical and Experimental Pathology 2014;7(9):6006-14.

39. Wang Q, Hardie R-A, Hoy AJ, van Geldermalsen M, Gao D, Fazli L, et al. Targeting ASCT2-mediated glutamine uptake blocks prostate cancer growth and tumour development. Journal of Pathology 2015;236(3):278-89. 
40. van Geldermalsen M, Wang Q, Nagarajah R, Marshall AD, Thoeng A, Gao D, et al. ASCT2/SLC1A5 controls glutamine uptake and tumour growth in triple-negative basal-like breast cancer. Oncogene 2016;35(24):3201-08.

41. Ye J, Kumanova M, Hart LS, Sloane K, Zhang H, De Panis DN, et al. The GCN2ATF4 pathway is critical for tumour cell survival and proliferation in response to nutrient deprivation. Embo Journal 2010;29(12):2082-96.

42. Wise DR, DeBerardinis RJ, Mancuso A, Sayed N, Zhang X-Y, Pfeiffer HK, et al. Myc regulates a transcriptional program that stimulates mitochondrial glutaminolysis and leads to glutamine addiction. Proc Natl Acad Sci U S A 2008;105(48):18782-87.

43. Reynolds MR, Lane AN, Robertson B, Kemp S, Liu Y, Hill BG, et al. Control of glutamine metabolism by the tumor suppressor Rb. Oncogene 2014;33(5):556-66.

44. Avissar NE, Sax HC, Toia L. In human entrocytes, GLN transport and ASCT2 surface expression induced by short-term EGF are MAPK, PI3K, and Rhodependent. Digestive Diseases and Sciences 2008;53(8):2113-25.

45. Jeon YJ, Khelifa S, Ratnikov B, Scott DA, Feng Y, Parisi F, et al. Regulation of Glutamine Carrier Proteins by RNF5 Determines Breast Cancer Response to ER Stress-Inducing Chemotherapies. Cancer Cell 2015;27(3):354-69.

46. Sinclair LV, Rolf J, Emslie E, Shi Y-B, Taylor PM, Cantrell DA. Control of aminoacid transport by antigen receptors coordinates the metabolic reprogramming essential for T cell differentiation. Nature Immunology 2013;14(5):500-08.

47. Gjymishka A, Palii SS, Shan J, Kilberg MS. Despite increased ATF4 binding at the C/EBP-ATF composite site following activation of the unfolded protein response, system A transporter 2 (SNAT2) transcription activity is repressed in HepG2 cells. Journal of Biological Chemistry 2008;283(41):27736-47. 


\section{Figure Legends}

\section{Figure 1. Remodeling of transcriptomic profiling in IDO-expressing tumor cells}

(A) Clustered RNA-seq expression data showing the fold change in the expression of genes up-regulated in both IDO1-transduced vs GFP-transduced HeLa cells cultured for 72h (left circles) and IFN $\gamma$-treated vs untreated WT HeLa cells cultured for $72 \mathrm{~h}$ (right circles), as indicated in the legend box on the right.

(B) RNA-seq profiles of solute carrier (SLC) (top) and amino acid metabolism (bottom) genes in IDO1-transduced vs GFP-transduced and IFN $\gamma$-treated vs untreated WT HeLa cells cultured for $48 \mathrm{~h}$ or $72 \mathrm{~h}$.

(C and D) WT, IFN $\gamma$-treated, GFP-transduced, IDO1-transduced and TDO2-transduced HeLa cells were cultured for $72 \mathrm{~h} . \operatorname{SLC1A5(L),SLC1A5(S),SLC1A5(M),SLC7A11}$ and SLC1A4 mRNA expression levels were analyzed by quantitative PCR, and are shown as fold change in expression relative to Actb. Bars represent the mean \pm SEM (C). Western Blot was performed with indicated antibodies and protein levels were quantified by densitometry (D). Data are representative of at least two independent experiments.

Figure 2. SLC1A5(L)- and SLC1A5(S)-transduced HeLa cells exhibit increased glutamine and tryptophan uptake

(A-C) Uptake experiments in WT, GFP-transduced, SLC1A5(L)-transduced and SLC1A5(S)-transduced HeLa cells were performed for $\left[{ }^{3} \mathrm{H}\right]$-glutamine (A) or $\left[{ }^{3} \mathrm{H}\right]$ tryptophan (B and C), in the presence or absence of SLC1A5 inhibitor BenSer over 10min or $3 \mathrm{~min}$, respectively. $\left[{ }^{3} \mathrm{H}\right]$-tryptophan uptake was also performed in the presence of excess unlabeled tryptophan (B). Bars represent the mean \pm SEM. ${ }^{*} \mathrm{p}<0.05 ; * * \mathrm{p}<0.01,{ }^{* * *} \mathrm{p}<$ 0.001. Data are representative of at least two independent experiments. 
Figure 3. Tryptophan depletion up-regulates SLC1A5 expression in a panel of IDO negative tumor cell lines

(A and B) WT HeLa cells were incubated in tissue culture medium containing indicated concentrations of tryptophan for $72 \mathrm{~h}(\mathbf{A})$ or $48 \mathrm{~h}(\mathbf{B}) . S L C 1 A 5(L)$ and $S L C 1 A 5(S)$ mRNA expression levels were analyzed by quantitative PCR, and are shown as fold change in expression relative to Gapd. Bars represent the mean \pm SEM (A). Western Blot was performed with indicated antibodies and protein levels were quantified by densitometry (B).

(C) HeLa, A431, DU145, DX3 and HPAF tumor cell lines were incubated in tissue culture medium depleted of tryptophan for $72 \mathrm{~h}$. Western Blot was performed with indicated antibodies and protein levels were quantified by densitometry.

(D) WT HeLa cells were incubated in tissue culture medium depleted of indicated amino acids for $48 \mathrm{~h}$. Western Blot was performed with indicated antibodies and protein levels were quantified by densitometry. Data are representative of at least two independent experiments.

\section{Figure 4. ATF4 mediates SLC1A5 up-regulation upon tryptophan withdrawal}

(A) RNA-seq transcriptome profiles of the integrated stress response genes in IDO1transduced vs GFP-transduced and IFN $\gamma$-treated vs untreated WT HeLa cells cultured for $48 \mathrm{~h}$ or $72 \mathrm{~h}$.

(B) Fold change in the expression of indicated genes in IFN $\gamma$-treated vs untreated WT HeLa cells cultured for 72h (top circles) and in IDO1-transduced vs GFP-transduced HeLa cells cultured for $72 \mathrm{~h}$ (bottom circles), as indicated in the legend box on the right.

(C and D) WT HeLa cells were incubated in tissue culture medium depleted of indicated amino acids (C) or in the presence of indicated tryptophan concentrations (D) for $48 \mathrm{~h}$. 
Western Blot was performed with indicated antibodies and protein levels were quantified by densitometry.

(E-G) WT and ATF4 knockdown (ATF4-KD) HeLa cells were incubated in tissue culture medium depleted of tryptophan for $48 \mathrm{~h}$. Western Blot was performed with indicated antibodies and protein levels were quantified by densitometry (E). SLC1A5(L), SLC1A5(S) and SLC1A5(M) mRNA expression levels (F), and SLC7A11 and SLC1A4 mRNA expression levels (G) were quantified by quantitative PCR, and are shown as fold change in expression in tryptophan-depleted vs complete tissue culture medium, relative to Hprt1. Bars represent the mean \pm SEM. ND, non-detected. Data are representative of at least two independent experiments.

Figure 5. Human T cells up-regulate SLC1A5 expression upon TCR stimulation, but not in response to tryptophan withdrawal

(A) WT HeLa, DU145, HPAF cells, and human $\mathrm{CD}^{+}$and $\mathrm{CD}^{+} \mathrm{T}$ cells, either stimulated $(+)$ or unstimulated (-) with plate-bound $\alpha \mathrm{CD} 3 / \mathrm{CD} 28$ antibodies, were incubated in tissue culture medium in the presence $(+)$ or in the absence $(-)$ of tryptophan for $48 \mathrm{~h}$. Western Blot was performed with indicated antibodies.

(B) WT HeLa and resting human $\mathrm{CD}^{+}$and $\mathrm{CD} 8^{+} \mathrm{T}$ cells were incubated in tissue culture medium depleted of tryptophan for $48 \mathrm{~h}$. SLC1A5(L) and SLC1A5(S) mRNA expression levels were analyzed by quantitative PCR, and are shown as fold change in expression in tryptophan-depleted vs complete tissue culture medium, relative to Hprt1. Bars represent the mean \pm SEM. ND, non-detected.

(C) NY-ESO-1-specific $\mathrm{CD}^{+} \mathrm{T}$ cell clone was stimulated with $\alpha \mathrm{CD} 3 / \mathrm{CD} 28$ antibodies or co-cultured with antigen presenting cells pre-pulsed with the indicated concentrations of NY-ESO-1 157-165 (V) peptide analogue. After 48h, SLC1A5 surface expression was 
assessed by flow cytometry using SLC1A5 cell surface RBD ligand staining. Bars represent the mean \pm SEM. MFI, mean fluorescence intensity. Data are representative of at least two independent experiments.

Figure 6. Expression of SLC1A5 correlates with the expression of tryptophandegrading enzymes in primary human tumors and is associated with decreased survival in brain lower grade glioma

(A) Spearman's rank correlation between SLC1A5 and WARS, TDO2, IDO1 or ATF4 gene expression in RNA-seq data of human liver hepatocellular carcinoma (LIHC), ovarian serous cystadenocarcinoma $(\mathrm{OV})$, glioblastoma multiforme (GBM), brain lower grade glioma (LGG), uterine corpus endometrial carcinoma (UCEC), adrenocortical carcinoma (ACC), cervical squamous cell carcinoma and endocervical adenocarcinoma (CESC), breast invasive carcinoma (BRCA) and kidney renal clear cell carcinoma (KIRC). The size of the circle indicates significance of correlation.

(B) Kaplan-Meier curves comparing survival of patients with brain lower grade glioma tumors expressing high or low levels of SLC1A5 (p-value=0.00006).

(C) Kaplan-Meier curves comparing survival of patients with brain lower grade glioma tumors expressing high or low levels of IDO1 (p-value=0.00053).

(D) Kaplan-Meier curves comparing survival of patients with brain lower grade glioma tumors expressing high or low SLC1A5 together with high or low levels of IDO1 (pvalue $=0.00005$ ). High and low expression of SLC1A5 or IDO1 was defined as above and below median expression, respectively. 
Author Manuscript Published OnlineFirst on September 20, 2016; DOI: $10.1158 / 0808-5472 . \mathrm{CAN}-155-3502 \underset{\mathrm{g}}{\log 2}$ Author manuscripts have been peer reviewed and accepted for publication but have not get beentedited.

Regulation of Apoptosis

OOTNF

OCEBPB

Hemopoiesis

Inflammatory Response

Fold

OOWARs OOYars oOsars

OOTXNIP OOCEBPG OOIFI16

OOCBX4 OOPMAIP1

OOHRK OODDIT3

OOSGPL1 OOCEBPG

OODHRS2 OOFAS

OOTNF OOJAG

OOFAS

OOEPAS1 OOIFI16

OOCEBPB OOCXCL2

OOTNF OONFE2L1

OOCXCL3 OOIGFBP4

t-RNA Aminoacylation

Omars oOcars oOgars

Monosaccharide Metabolism

$\begin{array}{lll}\text { OOATF3 } & \text { OOTNF } & \text { OOGFPT2 } \\ \text { OOGFPT1 } & \text { OOPCK2 } & \text { OOFUT1 }\end{array}$

Amino Acid and Carboxylic Acid Transport

OOSLC7A11 OOSLC1A4 OOSLC1A5 OOSLC6A9

Amino Acid and Carboxylic Acid Biosynthesis

$\mathrm{OOTH}$

OOASNS

IDO1 OOPSAT1 OOPSPH

Glutamine/ Glutamate Metabolism

OOGFPT1 OOGFPT2 OOGPT2 OOPYCR1
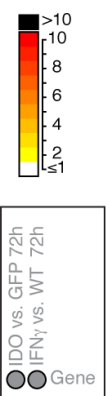

C

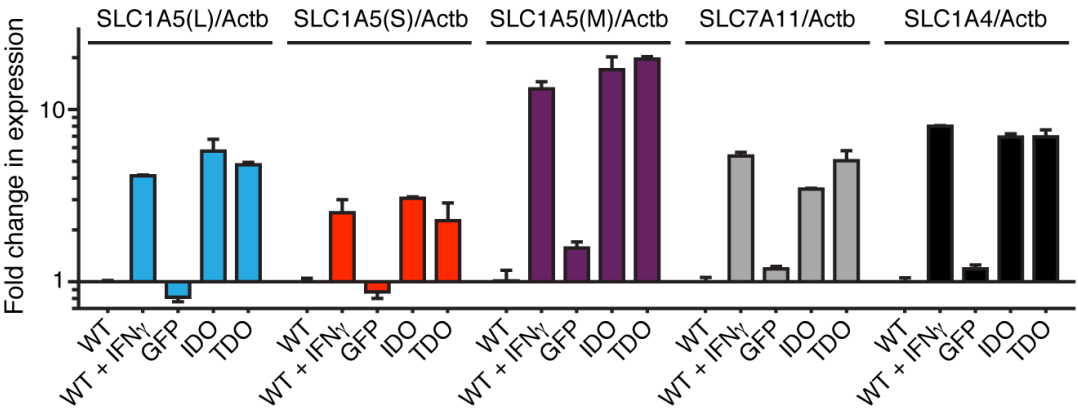

D

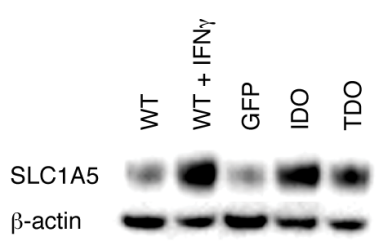

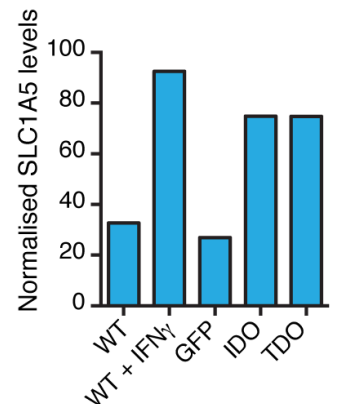
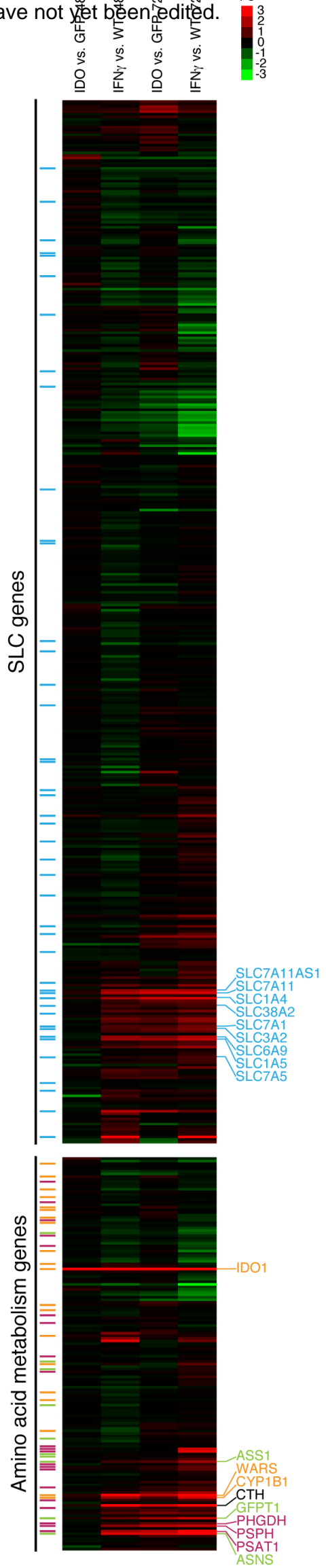

Known amino acid transporters Genes involved in Tryptophan metabolism Genes involved in Glutamine metabolism Genes involved in Serine metabolism 
A Author Manuscript Published OnlineFirst on September 20, 2016 ; DOI: 10.1158/0008-5472.CAN-15-3502

Author manuscripts have been peer reviewed and accepted for publication but have not yet been edited.
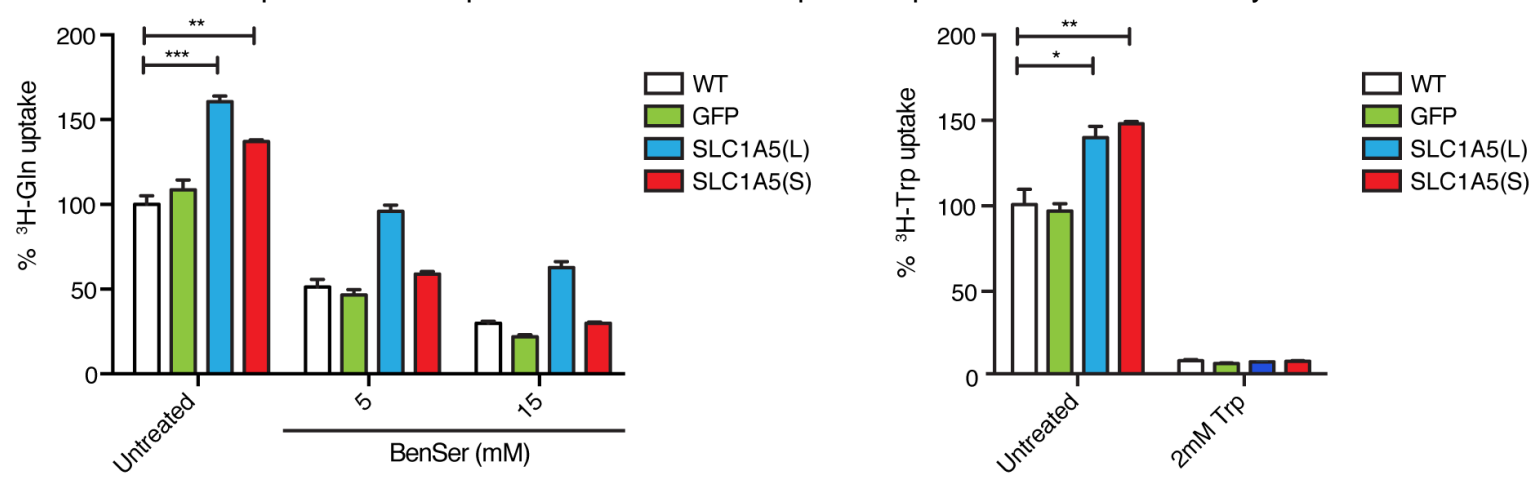

C

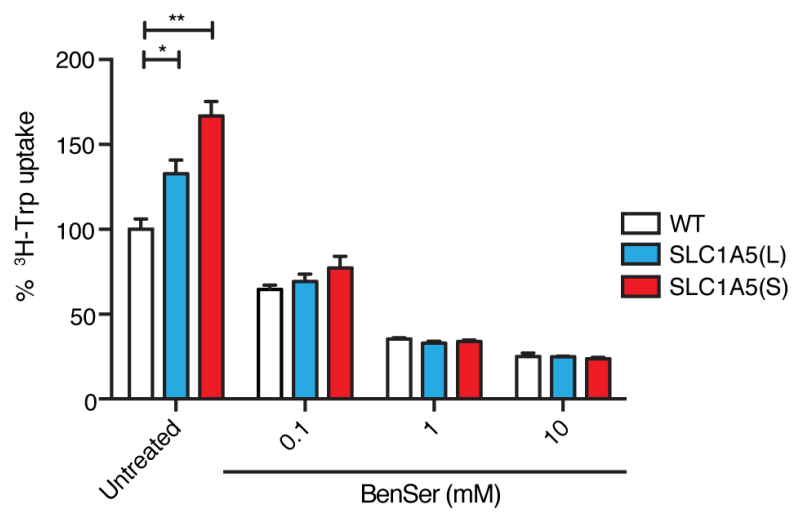


AuthôिManuscript Published OnlineFirst on September 20, 2016; DOI: 10.1158/0008-5472.CAN-15-3502

Author manuscripts have been peer reviewed and accepted for publication but have not yet been edited.

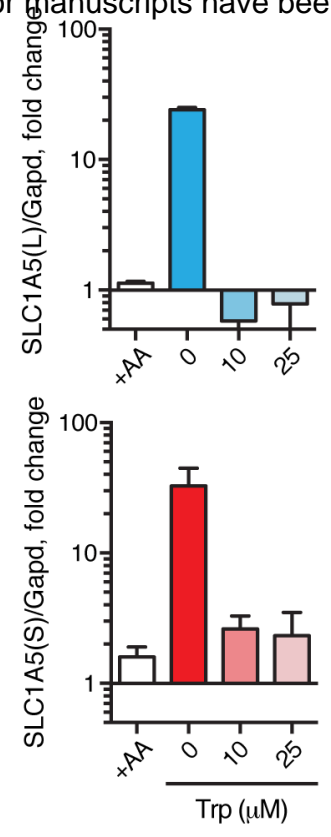

B
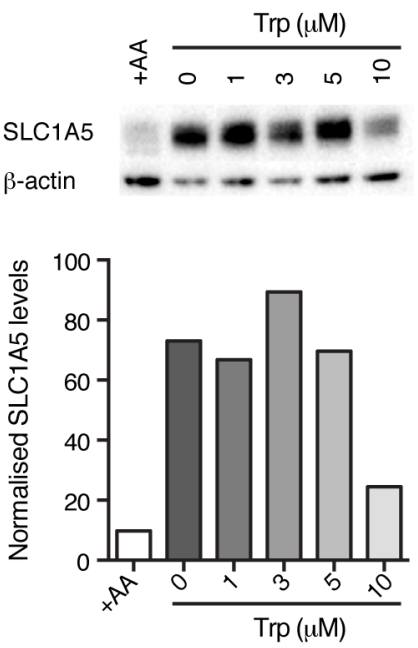

C
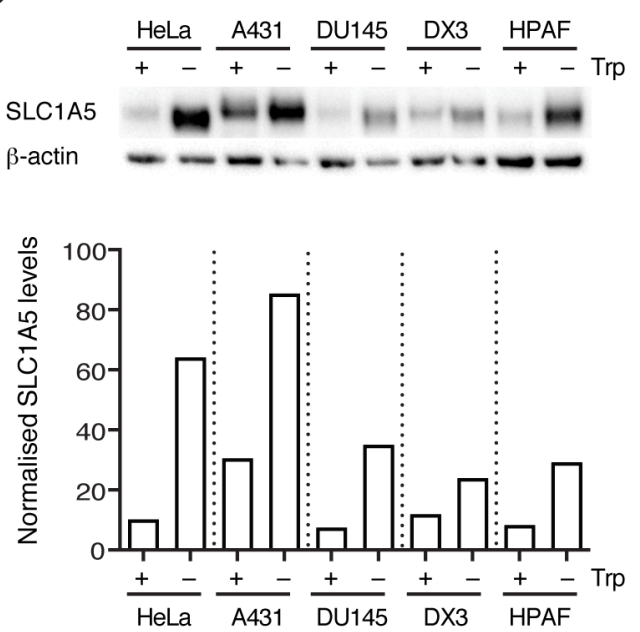

D
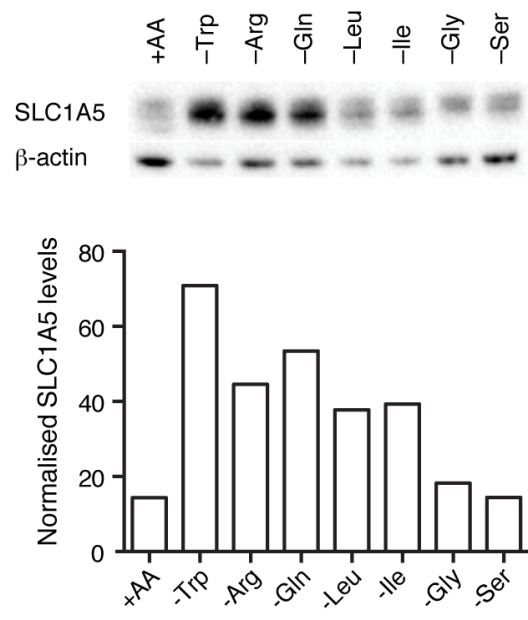


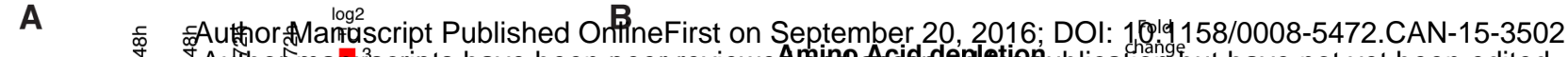

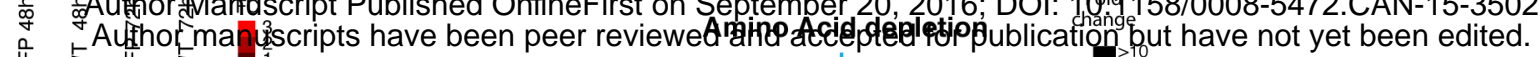

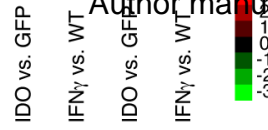
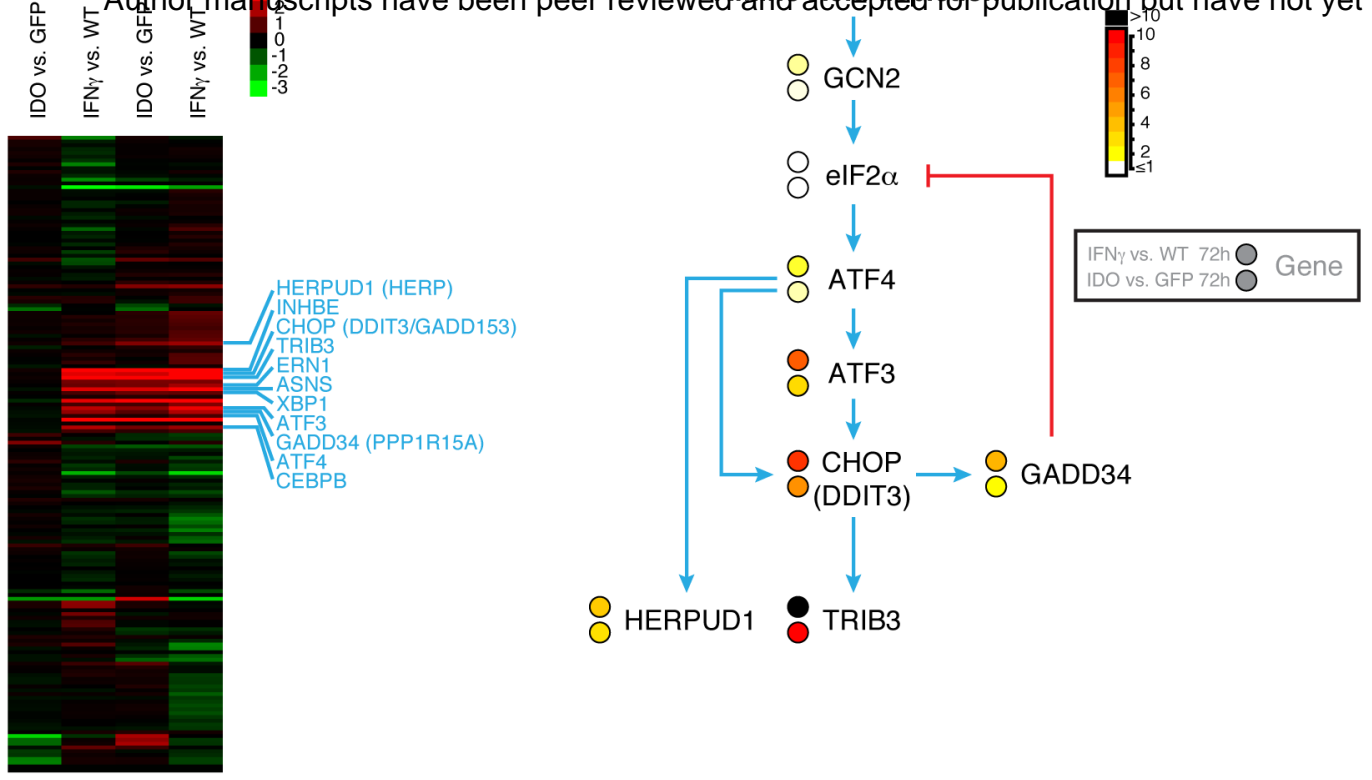

C
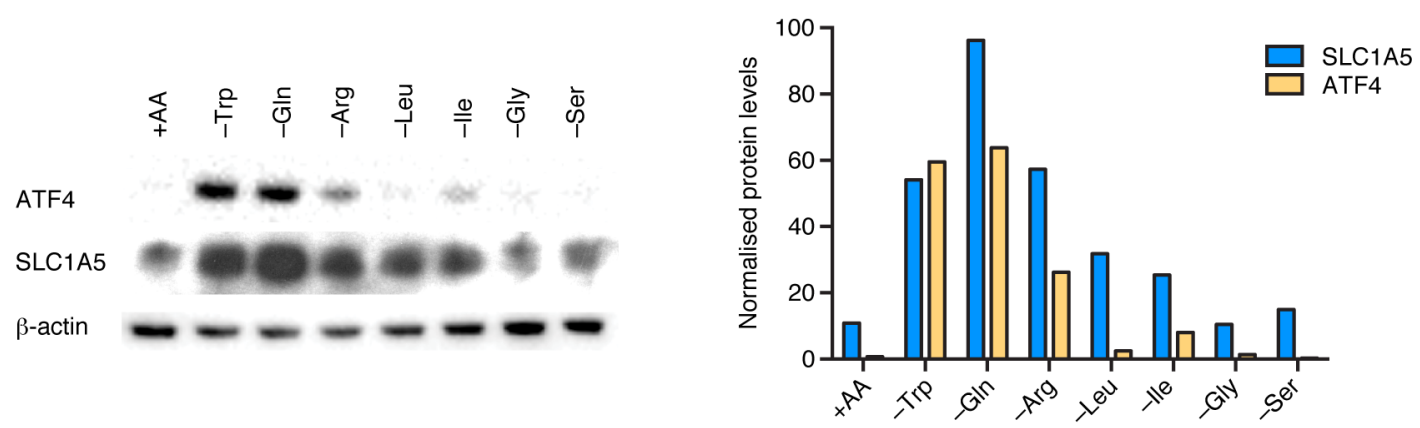

D
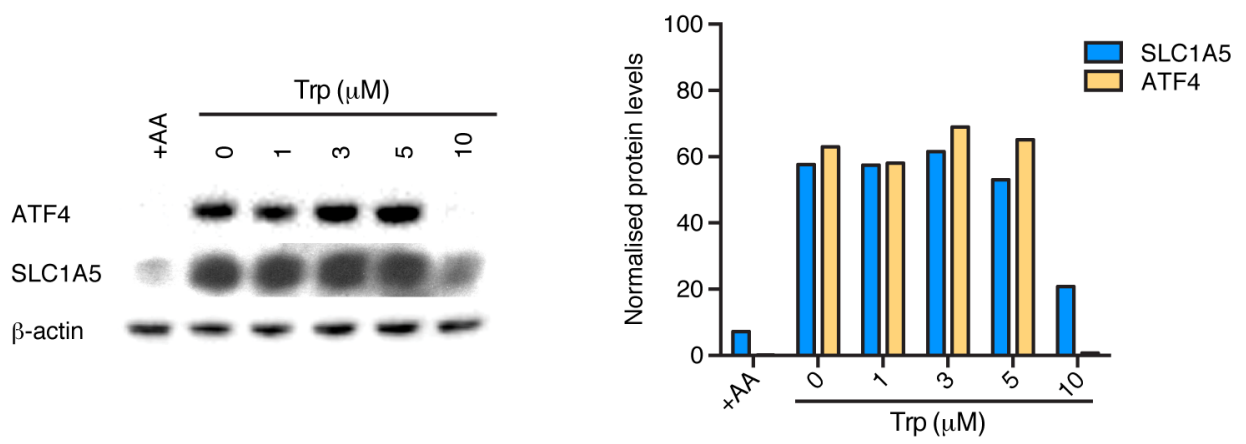

$\mathbf{E}$

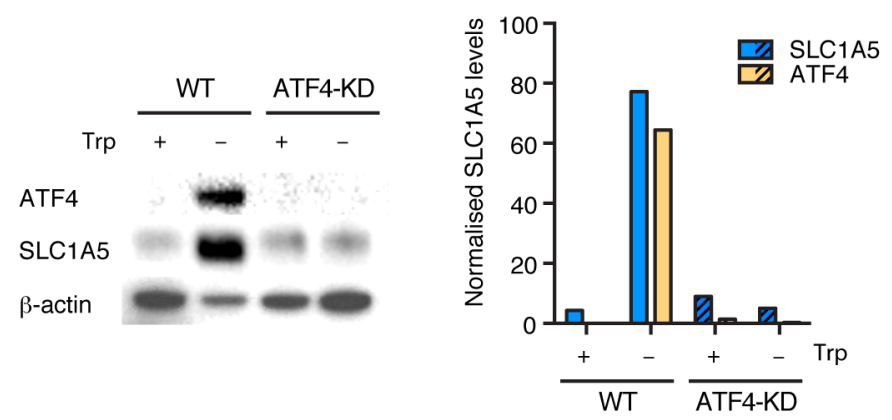

$\mathbf{F}$

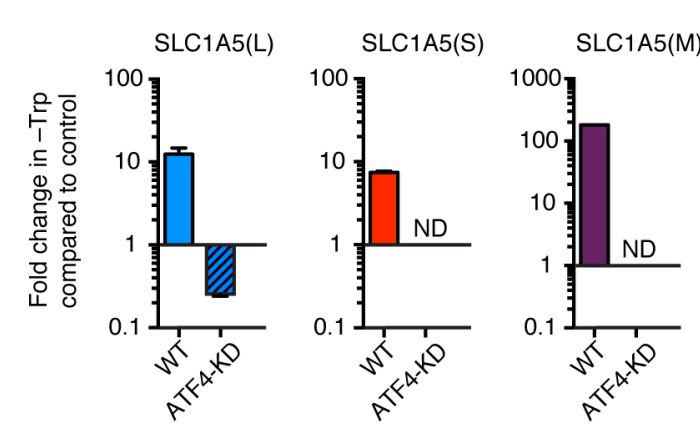

G

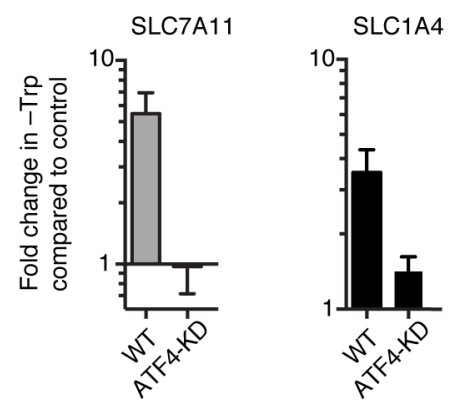


AutAor Manuscript Published OnlineFirst on September 20, 2016; DOI: 10.1158/0008-5472.CAN-15-3502 Author manuscripts have been peer reviewed and accepted for pyblication but have not yet been edited.
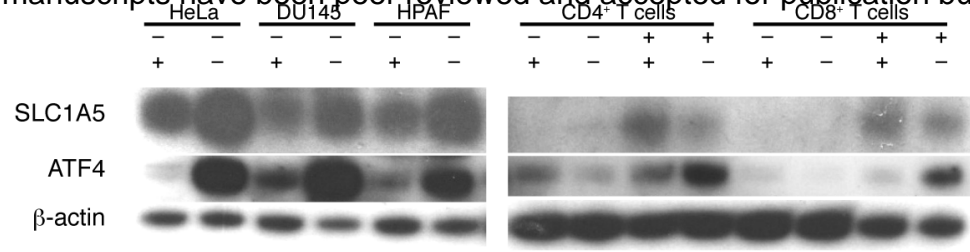

B

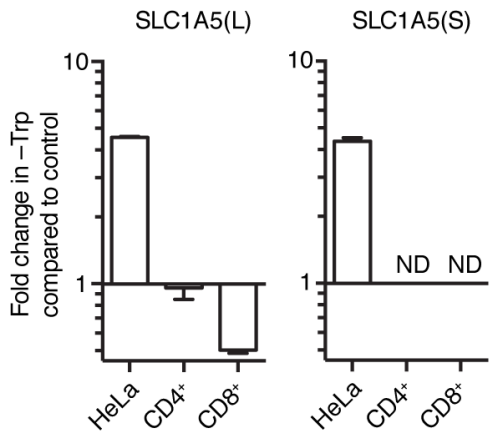

C $\alpha$ Trp $3 / C D 28$

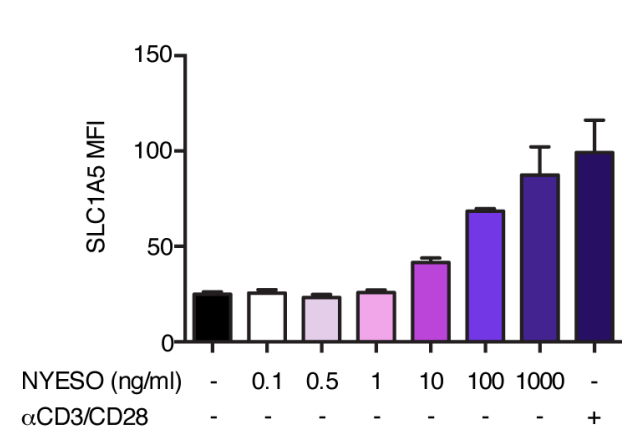


Author Manuscript Published OnlineFirst on September 20, 2016; DOI: 10.1158/0008-5472.CAN-15-3502

A Author manuscripts have been peer reviewed and accepted for publication but have not yet been edited.

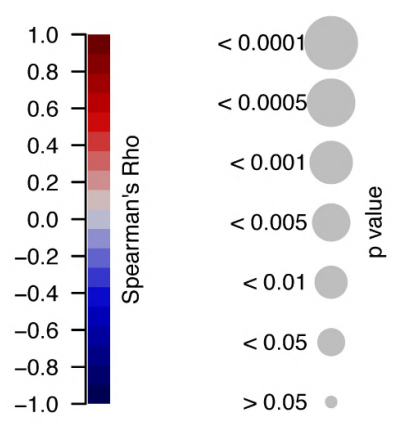

B

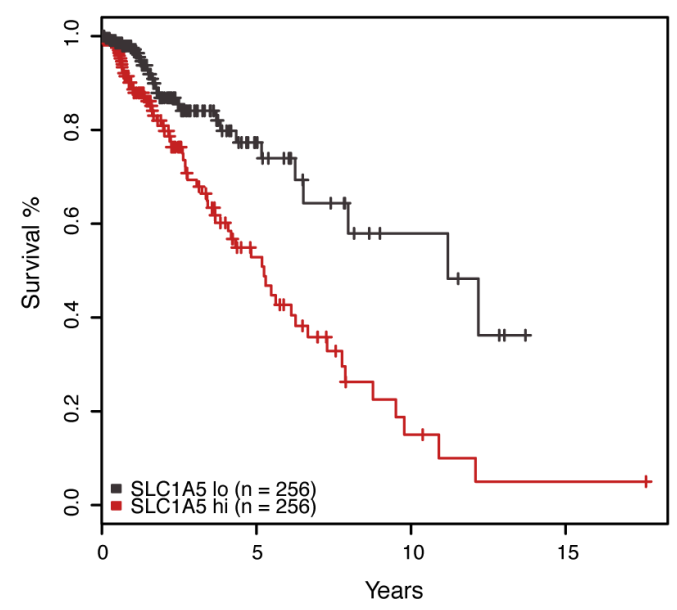

D

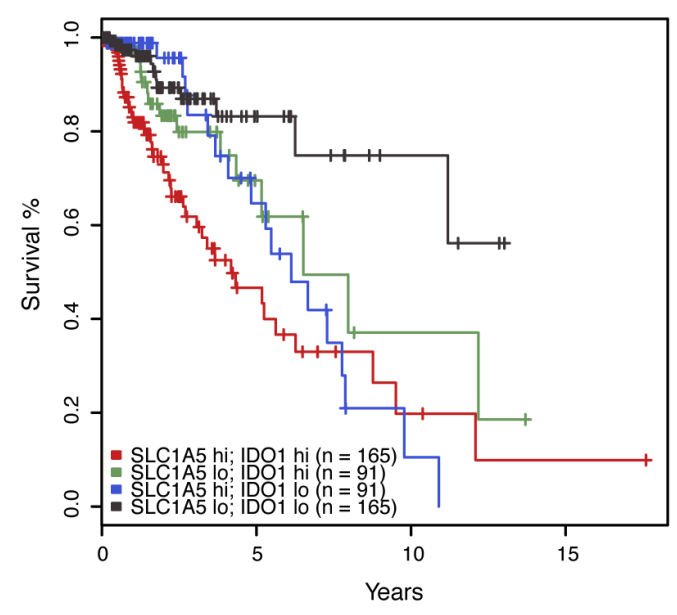

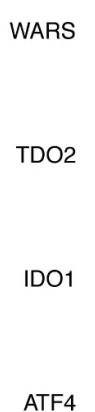

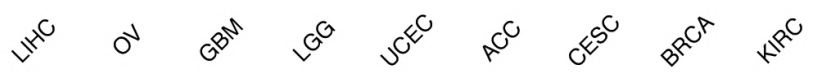

C

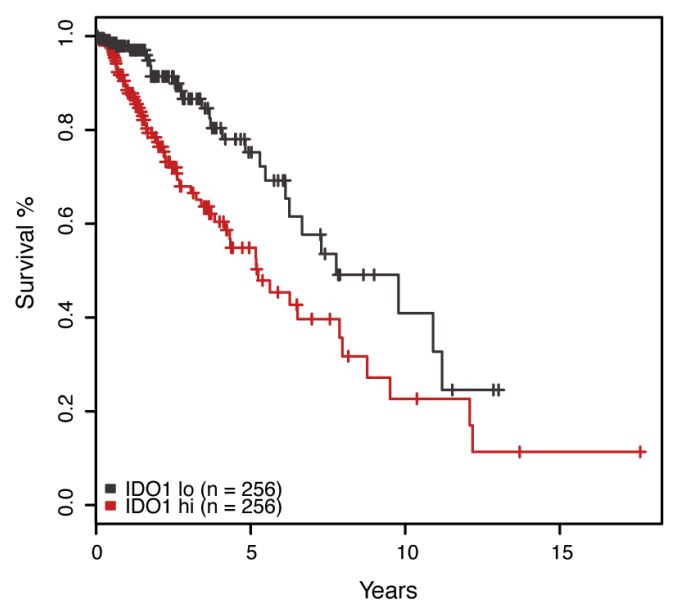




\section{Nutritional stress induced by tryptophan-degrading enzymes results in ATF4-dependent reprogramming of the amino acid transporter profile in tumor cells}

Elina Timosenko, Hemza Ghadbane, Jonathan D. Silk, et al.

Cancer Res Published OnlineFirst September 20, 2016.

Updated version

Supplementary Material

Author Manuscript
Access the most recent version of this article at: doi:10.1158/0008-5472.CAN-15-3502

Access the most recent supplemental material at: http://cancerres.aacrjournals.org/content/suppl/2016/09/17/0008-5472.CAN-15-3502.DC1

Author manuscripts have been peer reviewed and accepted for publication but have not yet been edited.

E-mail alerts Sign up to receive free email-alerts related to this article or journal.

Reprints and To order reprints of this article or to subscribe to the journal, contact the AACR Publications Subscriptions Department at pubs@aacr.org.

Permissions To request permission to re-use all or part of this article, use this link http://cancerres.aacrjournals.org/content/early/2016/09/17/0008-5472.CAN-15-3502.

Click on "Request Permissions" which will take you to the Copyright Clearance Center's (CCC) Rightslink site. 